\title{
Extremophilic Organisms as an Unexplored Source of
}

\section{Antifungal Compounds}

\author{
Charles H. Phoebe, Jr. ${ }^{a}$, Joan Combie ${ }^{b}$, Fred G. Albert ${ }^{b}$, Kim Van Tran $^{\mathrm{a}}$, Jessica Cabrera ${ }^{\mathrm{c}}$, \\ Heidi J. Correira ${ }^{\mathrm{c}}$, Yuehua Guo ${ }^{\mathrm{c}}$, Johanna Lindermuth ${ }^{\mathrm{c}}$, Nicole Rauert ${ }^{\mathrm{d}}$, \\ William Galbraith ${ }^{c}$ and Claude P. SelitrennikofF ${ }^{\mathrm{d} *}$ \\ ${ }^{a}$ Waters Corporation, Mail Stop CRD, \\ 24 Maple Street, Milford, MA 01757-3696, USA \\ ${ }^{\mathrm{b}}$ Montana Biotech Corporation, \\ 1740 East Baseline Road, Belgrade, MT 59714, USA \\ ${ }^{c}$ Alpha-Beta Technology, Inc., \\ One Innovation Drive, Worcester, MA 01569, USA \\ ${ }^{\mathrm{d}}$ MycoLogics, Inc., \\ 4200 East Ninth Avenue, Box B-111, Denver, CO 80262, USA
}

(Received for publication September 8, 2000)

\begin{abstract}
Extracts of the biomasses and fermentation broths of 217 extremophilic microorganisms isolated from a number of locales were screened for antifungal activity using whole-cell and mechanism-based in vitro assays. Importantly, eleven broth extracts had activity against several Candida species and Aspergillus fumigatus in whole-cell in vitro assays. One broth specifically inhibited $(1,3) \beta$-glucan synthase activity and four specifically inhibited ketol-isomerase activity, suggesting a mode of action of the antifungal compound(s) present in these extracts. The extract from one thermophile, a novel species of Pseudomonas, was fractionated, an active compound purified and its structure determined. The compound was identified as pyochelin, a previously identified iron-binding compound with heretofore undescribed antifungal activity. To our knowledge, this is the first report demonstrating that extremophiles synthesize compounds that have antifungal activity.
\end{abstract}

During the last three decades there has been a dramatic increase in the frequency of fungal infections in immunocompromised patients ${ }^{1-3)}$. Deep-seated mycoses are increasingly observed in patients undergoing organ transplants and in patients receiving aggressive cancer chemotherapy $^{4)}$. For example, the incidence of fungal infections following solid organ transplantation ranges from $5 \%$ in kidney recipients, between 15 and $35 \%$ in lung and heart recipients, and up to $40 \%$ in liver recipients ${ }^{4)}$. The most common pathogens associated with invasive fungal infections are the opportunistic yeast, Candida albicans, and the filamentous fungus, Aspergillus fumigatus ${ }^{5,6)}$. Also adding to the increase in the numbers of fungal infections is the emergence of Acquired Immunodeficiency Syndrome where virtually all patients become affected with some form of mycosis ${ }^{4,7}$. The most common organisms encountered in these patients are Cryptococcus neoformans, Pneumocystis carinii, and C. albicans ${ }^{7,8)}$. Current treatments for fungal infections are limited to three therapeutic classes: Amphotericin B (a macrolide polyene), which interacts with membrane sterols, flucytosine (a fluoropyrimidine), which interferes with protein and DNA biosynthesis and a variety of azoles (e.g., ketoconazole, itraconazole and fluconazole) that inhibit membrane-sterol biosynthesis ${ }^{4,99}$. Even though amphotericin B has a broad range of activity and is viewed as the "gold standard" of antifungal therapy, its use is limited due to infusion-related reactions and nephrotoxicity ${ }^{4,6}$. Flucytosine use is also limited due to the development of resistance and its narrow spectrum of activity while the wide-spread use of azoles is causing the emergence of clinically-resistant strains of Candida $\mathrm{spp}^{4,10)}$. Although advances in the formulation of

* Corresponding: claude.selitrennikoff@uchsc.edu 
amphotericin B have decreased its nephrotoxicity ${ }^{11}$, and new classes of antifungal agents such as the lipopeptides ${ }^{12)}$ and sordarins ${ }^{13)}$ are in various stages of clinical development, the impact of fungal infections in the clinical management of infected patients underscores the clear need for new antifungals:

The identification of new chemical entities is becoming more difficult. Historically, the screening of soil microorganisms and extracts obtained from terrestrial plants and animals has yielded novel natural products which themselves, or through chemical modification and synthesis, have been a rich source of drugs for the treatment of human disease ${ }^{14,15)}$. A review of the 520 newly-approved drugs reported between 1983 and 1994 indicates that 157 $(30 \%)$ are derived from unmodified natural products or semi-synthetic analogs ${ }^{16}$. Unfortunately, many potential sources have been screened numerous times, decreasing the probability of finding additional, useful lead compounds. One way to avoid this stumbling block is to screen organisms from unusual and previously ignored ecosystems.

Some of the oldest life-forms on Earth that withstand and even thrive in unusual ecosystems are known as "extremophiles". The unique genomes of these organisms are believed to have been adapted initially to suit the extreme environments that the earliest organisms on this planet faced. Today these organisms live in habitats that will support no other form of life. Most thermophilic extremophiles are moderate and grow at temperatures above $45^{\circ} \mathrm{C}^{17,18)}$; they are still able to grow but slowly between $25^{\circ} \mathrm{C}$ and $40^{\circ} \mathrm{C}^{18)}$. Research on thermophiles has been on-going for several decades with the most noted being the discovery of heat-stable DNA polymerase used in the polymerase chain reaction ${ }^{19}$. More recent work has been focused on other unusual ecosystems where extremophiles have been isolated from waters above $100^{\circ} \mathrm{C}$ in terrestrial hot springs and deep-sea thermal vents, at temperatures below $0^{\circ} \mathrm{C}$ in arctic waters, at immense pressure under several miles of water on the ocean floor, in the saturated salt environment of the Great Salt Lake, at very high osmolarities (e.g., high sugar concentrations), at $\mathrm{pH}$ values less than $\mathrm{pH} 2$ in drainage in certain mines and geothermal sulfur-rich springs, at $\mathrm{pH}$ values greater than $\mathrm{pH} \mathrm{11}$, and in media containing toxic compounds ${ }^{20)}$. The research thus far has focused on the isolation of "extremozymes" that might provide novel opportunities for biocatalysis in research and in industrial chemical processing $^{20,21)}$.

As far as we are aware, there are no reports of screening extremophiles for antifungal activity. The Montana Biotech
Corporation (MBC) in-house collection includes isolates from 1400 ecosystems from around the world. Many of the sampling sites were the thermal waters of Yellowstone National Park, which has the world's most diverse array of readily accessible, extreme microbial habitats.

In this manuscript, we report the screening of biomass and fermentation broth extracts of extremophiles for antifungal activity using whole-cell and in vitro enzyme assays. Importantly, we have identified fermentation broths of extremophiles and thermophiles that have potent activity against several human fungal pathogens.

\section{Materials and Methods}

Chemicals

UDP-glucose [glucose- $-{ }^{14} \mathrm{C}$ ] and UDP- $N$-acetylglucosamine [glucosamine $-{ }^{14} \mathrm{C}$ ] were obtained from New England Nuclear (Boston, MA). Yeast extract, casamino acids, tryptone and Bacto-Peptone were obtained from Difco (Detroit, MI). Beef extract, proteose peptone and malt extract were from Accumedia. SytoStain 13 was purchased from Molecular Probes (Eugene, OR). All other reagents and enzymes were purchased from Sigma (St. Louis, MO).

\section{Microorganisms}

The database covering the in-house collection of Montana Biotech Corporation was used to select organisms from a diversity of locations. Microorganisms were chosen for testing based on locality data, e.g., waters of $\mathrm{pH}$ between $\mathrm{pH} 3$ to $\mathrm{pH} 9$, temperatures from $20^{\circ} \mathrm{C}$ to $70^{\circ} \mathrm{C}$ and of various chemistries. Organisms that were either isolated in waters $>45^{\circ} \mathrm{C}$, could grow under laboratory conditions at $>45^{\circ} \mathrm{C}$, or were able to grow on exotic carbon or nitrogen sources or on toxic compounds were tested for antifungal activity (COMBIE, unpublished). Organisms were isolated and grown on media previously described ${ }^{23 \sim 26)}$. Zalerion arboricola (ATCC 20868), Emericella rugulosa (ATCC 58398), Actinomadura hibisca (ATCC 53557), Streptomyces nodosus (ATCC 14899), Aspergillus nidulans var. echinulatus (ATCC 16825), A. fumigatus (ATCC 16424), Candida albicans wild-type strain (ATCC 20402), C. glabrata (ATCC 48435), and polyene-resistant $C$. albicans (ATCC 38247) were obtained from the American Type Culture Collection and were reconstituted according to the directions provided. Each of the first five ATCC organisms is known to produce antifungal compounds (e.g., echinocandins) and was grown in $125 \mathrm{ml}$ of the medium recommended by ATCC in $500-\mathrm{ml}$ shaker flasks at $30^{\circ} \mathrm{C}$ for 
72 hours at $180 \mathrm{rpm}$. Fermentation broths and biomasses were separated and processed as described below. Cultures of Candida spp. cells were grown and harvested as described $^{26)}$.

Each extremophile was grown to stationary phase in 500 $\mathrm{ml}$ medium in one liter mini-fermentors with individually controlled air flow using a two port system (air inlet and outlet) at air flows of 250 to $1000 \mathrm{ml}$ air/minute. In general, microorganisms were incubated in the medium on which an organism was originally isolated. Media were adjusted to the $\mathrm{pH}$ approximating that of the original habitat. A loopful of cells from a storage slant was used to inoculate each mini-fermentor. Incubations were performed at the temperature of the original habitat. In general, organisms grown at $45^{\circ} \mathrm{C}$ or above were incubated for three days, while those at less than $45^{\circ} \mathrm{C}$ were incubated for four to seven days. Organism 8(C)X was isolated from Beach Springs Lake, Wyoming; the $\mathrm{pH}$ of the lake was $\mathrm{pH} 6.7$ while the ambient water temperature was $\sim 20^{\circ} \mathrm{C}$.

\section{Analysis of 16S rDNA}

Organism $8(\mathrm{C}) \mathrm{X}$ was harvested and genomic DNA isolated. The $16 \mathrm{~S}$ rRNA encoding gene was PCR-amplified from genomic DNA. Primers used for the amplification corresponded to $E$. coli positions 005 and 1540. The sequence of the amplification products was determined on an ABI Prism 377 DNA Sequencer and analyzed using PE/Applied Biosystems DNA editing and assembly software ${ }^{28)}$ by Dr. J. BARTELL of MIDI Labs (Newark, DE).

\section{Extract Preparation}

Ethyl Acetate Extract: After incubation, each sample was centrifuged at $1900 \mathrm{~g}$ for 30 minutes to separate the supernatant (broth) and cells (biomass). Each broth sample was passed through a $0.22 \mu \mathrm{m}$ filter and extracted with an equal volume of ethyl acetate. The extracted broth sample (aqueous phase) was discarded, the ethyl acetate extract was reduced to $5 \mathrm{ml}$ under a stream of dry air at $27^{\circ} \mathrm{C}$, transferred to pre-weighed screw-top glass tubes $(16 \times 100$ $\mathrm{mm}$ ) and taken to dryness in vacuo at ambient temperature in a SpeedVac concentrator (Savant Instruments, Inc., Holbrook, NY). The weight of each ethyl acetate extract was determined, DMSO was added to yield $100 \mathrm{mg}$ extract $/ \mathrm{ml}$, solutions were transferred to individual wells of deep 96-well plates and stored frozen at $-20^{\circ} \mathrm{C}$. Uninoculated media were processed in the same manner.

Ethanol extract: The biomass from each fermentation was transferred to a $50-\mathrm{ml}$ disposable centrifuge tube and brought to a final volume of $40 \mathrm{ml}$ with absolute ethanol. Tubes were shaken for 10 minutes and then centrifuged
$(1700 \mathrm{~g})$ for 30 minutes. The ethanolic supernatants were decanted into $40-\mathrm{ml}$ glass vials, the extracted biomasses discarded, and each solution reduced to $\sim 2 \mathrm{ml}$ under a stream of dry air at $27^{\circ} \mathrm{C}$. The concentrated samples were transferred to pre-weighed screw top glass tubes $(16 \times 100 \mathrm{~mm})$ and taken to dryness in vacuo at ambient temperature in a SpeedVac concentrator. The weight of each ethanolic extract was determined, the extracts dissolved in one $\mathrm{ml} 50 \%(\mathrm{v} / \mathrm{v})$ aqueous methanol and $500 \mu \mathrm{l}$ of each sample dispensed into individual wells of deep 96well plates. The plates were placed into a SpeedVac concentrator and the samples reduced to dryness. Fifty $\mu 1$ DMSO was added to each well to dissolve each extract and the plates stored frozen at $-20^{\circ} \mathrm{C}$.

\section{In vitro Antifungal Whole-cell Assays}

\section{C. albicans Protoplast Regeneration Assay}

Inhibition of C. albicans (ATCC 20402) protoplast cellwall generation and growth was measured using an agar overlay method. Protoplasts were released from mid-log cells, grown in $1 \%(\mathrm{w} / \mathrm{v})$ yeast extract, $2 \%(\mathrm{w} / \mathrm{v})$ peptone, $2 \%$ (w/v) dextrose (YPD), using lyticase $(0.38 \mathrm{mg} / \mathrm{ml}$ in $0.6 \mathrm{M} \mathrm{KCl}, 50 \mathrm{~mm} \mathrm{NaHPO}, 5 \mathrm{~mm}$ tetrasodium EDTA, and $0.34 \%[\mathrm{v} / \mathrm{v}] 2-$ mercaptoethanol, $37^{\circ} \mathrm{C}$ ) to digest the cell wall. Protoplasts were washed by centrifugation and resuspended in $0.6 \mathrm{M} \mathrm{KCl}$. Test samples or vehicle $(2.5 \mu \mathrm{l})$ were placed in 96-well microtiter plate wells and molten agar $(75 \mu \mathrm{l} ; 1.5 \%[\mathrm{w} / \mathrm{v}]$ agar in YPD containing $0.6 \mathrm{M}$ $\mathrm{KCl}$ ) was added and allowed to cool. Protoplasts were added in a molten agar layer $(30 \mu \mathrm{l}$ containing $2 \times 10^{5}$ cells $/ \mathrm{ml}$ in $0.5 \%$ w/v] agar in YPD with $0.6 \mathrm{M} \mathrm{KCl}$ ). The microtiter plates were incubated at $30^{\circ} \mathrm{C}$ and microscopically scored for protoplast regeneration and growth after 24 and 48 hours of incubation.

\section{C. albicans Whole-cell Agar Diffusion Assay}

Inhibition of $C$. albicans (ATCC 20402) cell growth was measured using an agar overlay method. Test samples, standard inhibitors, or controls $(2.5 \mu \mathrm{l})$ were placed in 96well microtiter plate wells and molten agar $(75 \mu \mathrm{l} ; 1.5 \%$ $[\mathrm{w} / \mathrm{v}]$ agar in YPD) was added and allowed to cool. $C$. albicans cells, obtained as described above, were added in an agar layer $\left(30 \mu \mathrm{l}\right.$ containing $3 \times 10^{5} \mathrm{cells} / \mathrm{ml}$ in $0.5 \%$ [w/v] agar in YPD) and allowed to cool. The microtiter plates were incubated at $30^{\circ} \mathrm{C}$ and evaluated visually at $40 \sim 48$ hours using an inverted light microscope.

\section{C. albicans Broth Assays}

All Candida spp. broth assays were performed in RPMI 
1640 medium with glutamine, without bicarbonate, buffered with MOPS to $\mathrm{pH}$ 7.0. Inhibition of Candida spp. by biomass and broth extracts was determined as follows: C. albicans wild-type (ATCC 20402), C. glabrata (ATCC 48435), and polyene-resistant $C$. albicans (ATCC 38247) cells were grown to mid-log phase, washed by centrifugation, resuspended in medium, and added to microtiter plate wells at $1 \times 10^{3}$ cells per well $(\sim 110 \mu \mathrm{l})$. Extracts or vehicle were added $(2 \mu \mathrm{l})$, plates were incubated at $30^{\circ} \mathrm{C}$ with shaking for $15 \sim 16$ hours and washed. Cells were resuspended to the original volume with RPMI containing $0.165 \mathrm{M}$ MOPS and SytoStain 13 added ( $10 \mu \mathrm{l}$ of $10 \mu \mathrm{M}$ in RPMI-0.165 M MOPS). Fluorescence was measured using a 7620 Microplate Fluorometer (Cambridge Technology, Inc., Cambridge, MA) with an excitation wavelength of $485 \mathrm{~nm}$ and an emission wavelength of $530 \mathrm{~nm}$.

\section{A. fumigatus Broth Assay}

The microtiter assay procedure was a modification of the NCCLS protocol M-27T. Liquid $(200 \mu 1)$ RPMI 1640 medium with glutamine and phenol red, without bicarbonate, buffered with MOPS to $\mathrm{pH} 7.0$, in 96-well microtiter plates was inoculated with $2 \times 10^{3} \mathrm{~A}$. fumigatus (ATCC 16424) conidia per well (conidia were obtained from $-80^{\circ} \mathrm{C}$ glycerol stocks). Samples ( $2 \mu \mathrm{l}$ prepared in DMSO) were added to each well and plates incubated at $37^{\circ} \mathrm{C}$ for 48 hours. The amount of growth was determined using a microtiter optical plate reader at $680 \mathrm{~nm}$ or, alternatively, by scoring each well by eye with the aid of a light microscope.

\section{Enzyme Assays}

$(1,3) \beta$-glucan synthase activity (EC.2.4.1.34; UDPglucose; $1,3-\beta$-D-glucan 3 - $\beta$-glucosyl transferase) was assayed as described by WoOD et al. ${ }^{27)}$. Chitin synthase activity (EC.2.4.1.16; chitin: UDP-acetylamino-deoxyglucosyl transferase) from $C$. albicans was assayed essentially as described in YARDEN and YANOFSKY ${ }^{29)}$. Ketolisomerase activity (EC. 5.3.1.19: 2-amino-2-deoxy-Dglucose-6-phosphate ketol-isomerase [amino transferring]) was measured using lysates from A. fumigatus as enzyme sources as described by SELITRENNIKOFF and OSTROFF ${ }^{30)}$. The inhibitor, 6-diazo-5-oxo-norleucine, was used as a control for enzyme inhibition and had an $\mathrm{IC}_{50}$ of $17 \mathrm{ng} / \mathrm{ml}$ $(\sim 0.1 \mu \mathrm{M})$. The amounts of protein in cell extracts were determined using the Bio-Rad kit following the manufacturer's directions.
Fractionation of Organism $8(\mathrm{C}) \mathrm{X}$

To identify the active compound present in the extract from $8(\mathrm{C}) \mathrm{X}$, the organism was grown at $25^{\circ} \mathrm{C}$ in $80500-\mathrm{ml}$ fermentors as described above and the medium was extracted three times with EtOAc ( $\sim 40$ liters, total). The combined organic extracts were evaporated in vacuo to dryness $(\sim 1.5 \mathrm{~g})$. The extract was separated using automated preparative reversed-phase HPLC and solid phase extraction (described in the next section) and $40-\mathrm{ml}$ fractions collected. One $\mathrm{ml}$ aliquots of each fraction were taken to dryness in vacuo, re-suspended in DMSO (10 $\mu \mathrm{l})$ and tested for antifungal activity using the $C$. albicans whole cell assay. Two active fractions were further separated by HPLC and three resulting active fractions analyzed by NMR.

\section{Analytical Methods}

${ }^{1} \mathrm{H}$ and ${ }^{13} \mathrm{C}$ NMR spectra were obtained on either a Bruker DRX 500 or Bruker 400 spectrometer, with $\mathrm{CDCl}_{3}$ as a solvent. Negative-ion and positive-ion ESI mass spectra were recorded on a Perkin-Elmer Sciex API 165, single quadrupole instrument. Analytical reversed-phase HPLC-ELSD-ESIMS of the active fractions was performed on a LiChrosphere 60 , RP Select B column $(4 \times 250 \mathrm{~mm}$, $5 \mu \mathrm{m}$ particle size, Merck, employing a 30 minute linear gradient elution from (eluent A) $5 \mathrm{~mm}$ ammonium formate in water to (eluent $B$ ) acetonitrile/methanol (1:1) $(\mathrm{A} / \mathrm{B}=85 / 15$ to $0 / 100)$. The flow rate was $0.9 \mathrm{ml} / \mathrm{minute}$. Automated preparative reversed-phase chromatography/ solid phase extraction trapping was performed on a SEPBOX (AnalytiCon). The initial preparative fractionation was performed on a $\mathrm{C}-4$ reversed-phase column $(50 \times 250 \mathrm{~mm})$ employing a 30 minute linear gradient elution from (eluent A) $5 \mathrm{~mm}$ ammonium formate in water to (eluent $\mathrm{B}$ ) methanol $(\mathrm{A} / \mathrm{B}=0 / 100$ to $100 / 0$, hold for 20 minutes). The flow rate was $109 \mathrm{ml} / \mathrm{minute}$ and eighteen fractions were collected. Subsequent subfractionation was performed on a $\mathrm{C}-18$ reversed-phase column $(25 \times 250 \mathrm{~mm})$ employing various linear gradients of $5 \mathrm{~mm}$ ammonium formate in water and methanol (Figure $3 \mathrm{~A}$ and $3 \mathrm{~B}$ ). The identification of the active compound in fractions $\mathrm{K} 7, \mathrm{~K} 8$ and $\mathrm{L} 7$ by MS and NMR analyses was performed by AnalytiCon AG (Potsdam, Germany).

\section{Results}

Extremophiles include groups of organisms that have not been screened as sources of antifungal agents, thus making them potential sources of novel compounds. We selected 
Fig. 1. Diversity of microbial habitats screened.

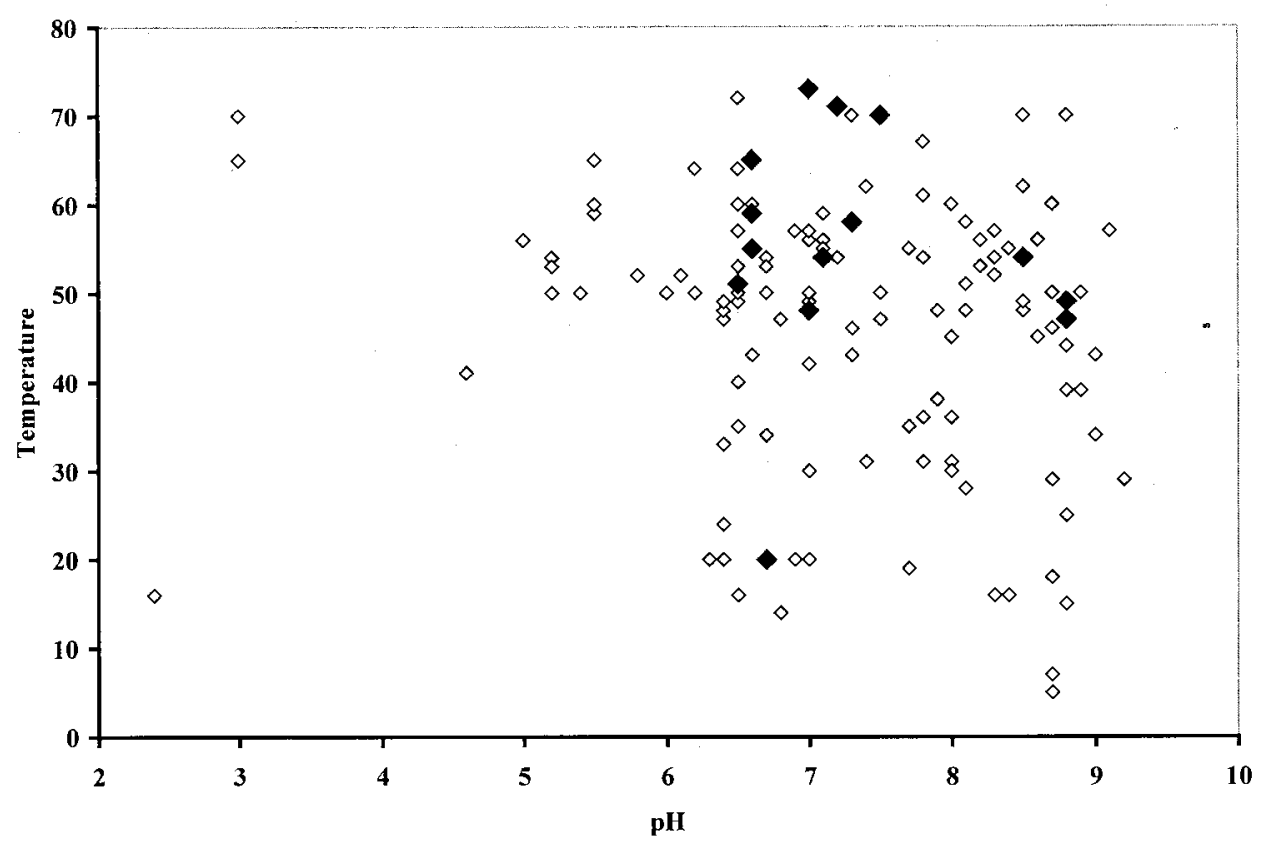

Original habitat $\mathrm{pH} v s$. habitat temperature for organisms in this study. Open symbols represent all 217 organisms. Closed symbols represent organisms with anti-fungal activity. In some instances, several organisms are represented by one symbol at the same $\mathrm{pH}$ and temperature.

217 microorganisms for screening for antifungal compounds from the Montana Biotech collection based on the properties described in the Materials and Methods. A plot of the $\mathrm{pH}$ of the habitat and the temperature of the thermal feature of each of the 217 organisms is shown in Figure 1. The organisms that had antifungal activity, as described below, are indicated by closed symbols.

Each microorganism was grown and the fermentation broths and biomasses processed as detailed in the Materials and Methods. Extracts from each of five organisms known to produce antifungal compounds were similarly prepared to serve as controls. A total of 217 fermentation broths and biomass extracts and the 5 antifungal-producing organisms were screened for antifungal activity. Twenty-nine broth extracts (13\% of total) and each of the antifungal-producing control organisms had activity against $C$. albicans (results not shown). To confirm these observations, a second fermentation of these 29 microorganisms and the five antifungal-producing organisms was prepared and an ethyl acetate extract made from the spent broth as well as an ethanolic extract of each biomass. As expected, each extract of the fermentation broth and/or biomass of the five antifungal-producing organisms had antifungal activity in both the whole-cell and the protoplast-regeneration assays (Table 1). Of the 29 microorganisms re-tested, the ethyl acetate extracts of only 15 were active against $C$. albicans (Table 1). The remaining 14 microorganisms failed to reproduce the original activity for reason(s) not understood (results not shown). None of the biomass extracts was active in the $C$. albicans whole-cell agar diffusion assay while seven were active against protoplasts (Table 1).

The ethyl acetate extracts of the fermentation broths from the 15 active microorganisms were tested against a polyene-resistant strain of $C$. albicans as described in the Materials and Methods. The broth extracts of four organisms were not active (not shown); none of these four organisms was considered further. Extracts of the fermentation broths of the eleven remaining microorganisms (and the five control antifungal-producing organisms) were tested further to determine their breadth of activity and to elucidate possible mechanisms of antifungal activity. These results are presented in Table 2. Again as expected, each of the five control organisms was active. Note that extracts of four microorganisms were also active against $C$. glabrata, showing that these extracts had broad anti-candidal activity. Importantly, the ethyl acetate extracts 
Table 1. Activity of extracts in C. albicans protoplast regeneration and whole-cell assays*.

\begin{tabular}{|l|c|c|c|c|}
\hline \multicolumn{1}{|c|}{ Microorganism } & \multicolumn{2}{c|}{ Broth Extract } & \multicolumn{2}{c|}{ Biomass Extract } \\
\hline 253 & Protoplast & Whole-cell & Protoplast & Whole-cell \\
\hline $8(\mathrm{C}) \mathrm{X}$ & WALL & RCS & N & $\mathrm{N}$ \\
\hline $24(\mathrm{~B}) \mathrm{F}$ & WALL & KILL & WALL & $\mathrm{N}$ \\
\hline $30(\mathrm{~A}) \mathrm{X}$ & WALL & RCN & RCN & $\mathrm{N}$ \\
\hline 236 & WALL & RCN & WALL & $\mathrm{N}$ \\
\hline 237 & WALL & KILL & $\mathrm{N}$ & $\mathrm{N}$ \\
\hline 244 & KILL & RCN & $\mathrm{N}$ & $\mathrm{N}$ \\
\hline $245(\mathrm{~B})$ & KILL & RCN & RCN & $\mathrm{N}$ \\
\hline 248 & KILL & RCN & N & $\mathrm{N}$ \\
\hline $252(\mathrm{~A})$ & WALL & RCN & WALL & $\mathrm{N}$ \\
\hline 430 PER & KILL & RCN & N & $\mathrm{N}$ \\
\hline 23 X & WALL & KILL & N & N \\
\hline $56(B)$ X & WALL & RCN & RCN & N \\
\hline 197 PER & RCN & RCS & N & N \\
\hline 88 X & WALL & KILL & WALL & N \\
\hline Zalerion arboricola & KILL & KILL & N & N \\
\hline Emericella rugulosa & KILL & KILL & KILL & KILL \\
\hline Streptomyces nodosus & N & N & KILL & KILL \\
\hline A. nidulans & N & N & WALL & KILL \\
\hline Actinomadura hibisca & KILL & N & N & N \\
\hline
\end{tabular}

* The indicated microorganisms were grown, the broths and biomasses isolated and extracted as described Materials and Methods. Each extract was tested in the C. albicans protoplast and whole-cell assays as described in the Methods. Each assay was scored as follows: $\mathrm{N}=$ no effect; $\mathrm{RCS}=$ reduced colony size; $\mathrm{RCN}=$ reduced colony number; WALL= individual protoplasts present but unable to regenerate a cell wall and grow; or KILL= no protoplasts or colonies present.

of broths from $8(\mathrm{C}) \mathrm{X}, 430$ PER and 197 PER were active against $A$. fumigatus, $C$. glabrata and wild-type $C$. albicans.

In an effort to ascribe a mechanism of action to the antifungal compounds in each extract, we tested broth extracts from each of the eleven active microorganisms for inhibition of chitin synthase, $(1,3) \beta$-glucan synthase and ketol-isomerase activities (each activity is essential for fungal cell-wall formation) as described in the Materials and Methods. These results are summarized in Table 3. None of the extracts inhibited chitin synthase activity (results not shown). The extract from 430 PER inhibited $(1,3) \beta$-glucan synthase activity and the extracts from broths of $8(\mathrm{C}) \mathrm{X}, 248,237$, and $88 \mathrm{X}$ specifically inhibited ketolisomerase activity. The extracts from broths of 236, 252(A), and 197 PER inhibited both $(1,3) \beta$-glucan synthase and ketol-isomerase activities. The remaining three extracts did not inhibit $(1,3) \beta$-glucan synthase or ketol-isomerase activities (not shown) and their mode of action is (are) unknown at this time.

Based on the observation that the extract from organism $8(\mathrm{C}) \mathrm{X}$ had broad antifungal activity against $C$. albicans, polyene-resistant $C$. albicans, $C$. glabrata, and $A$. fumigatus, we decided to identify the active component(s) present in this extract. Previously, we had determined that organism $8(\mathrm{C}) \mathrm{X}$ grew between $\mathrm{pH} 4$ and $\mathrm{pH} 9$, and had a $\mathrm{T}_{\max }$ of $\sim 50^{\circ} \mathrm{C}$ (unpublished results). Importantly, the $16 \mathrm{~s}$ rDNA nucleotide sequence from organism $8(\mathrm{C}) \mathrm{X}$ was similar but not identical to Pseudomonas veronii (not shown), indicating that organism $8(\mathrm{C}) \mathrm{X}$ is a novel species of Pseudomonas. Details of the species identification of this and other antifungal producing microorganisms will be presented elsewhere (SELITRENNIKOFF, et al., in preparation).

Second, we pooled the broths from 80 500-ml 
Table 2. Effect of ethyl acetate broth extracts on the growth of C. albicans, C. glabrata and A. fumigatus*.

\begin{tabular}{|l|c|c|c|}
\hline \multicolumn{1}{|c|}{ Microorganism } & C. albicans & C. glabrata & A. fumigatus \\
\hline 253 & KILL & N & N \\
\hline $8(\mathrm{C}) \mathrm{X}$ & KILL & KILL & KILL \\
\hline $24(\mathrm{~B}) \mathrm{F}$ & KILL & $\mathrm{N}$ & $\mathrm{N}$ \\
\hline 236 & KILL & $\mathrm{N}$ & $\mathrm{N}$ \\
\hline 237 & KILL & $\mathrm{N}$ & $\mathrm{N}$ \\
\hline 244 & KILL & RCN & $\mathrm{N}$ \\
\hline 248 & KILL & $\mathrm{N}$ & $\mathrm{N}$ \\
\hline $252(\mathrm{~A})$ & KILL & $\mathrm{N}$ & $\mathrm{N}$ \\
\hline 430 PER & KILL & KILL & KILL \\
\hline 197 PER & KILL & KILL & KILL \\
\hline 88 X & RCN & N & N \\
\hline Zalerion arboricola & KILL & KILL & KILL \\
\hline Emericella rugulosa & KILL & KILL & KILL \\
\hline Streptomyces nodosus $\dagger$ & KILL & KILL & KILL \\
\hline Aspergillus nidulans $\dagger$ & KILL & KILL & N \\
\hline Actinomadura hibisca & N & KILL & N \\
\hline
\end{tabular}

* The indicated organisms were grown, the broths extracted with ethyl acetate and the extracts tested for inhibition of growth of the above fungi as described in Materials and Methods. The effects of the extracts were evaluated as follows: $\mathrm{N}=$ no effect; $\mathrm{RCS}=$ reduced colony size; $\mathrm{RCN}=$ reduced colony number; or KILL= no visible growth.

$\dagger$ Results are for the ethanolic extracts of the biomass.

Table 3. The effect of broth extracts on $(1,3) \beta$-glucan synthase and ketol-isomerase activities*.

\begin{tabular}{|l|c|c|c|}
\hline Microorganism & $\begin{array}{c}(1-3) \beta \text {-glucan synthase activity } \\
\cdot \mathrm{IC}_{50}(\mathrm{mg} / \mathrm{mL})\end{array}$ & $\begin{array}{c}\text { Ketol-isomerase activity } \\
\mathrm{IC}_{50}(\mu \mathrm{g} / \mathrm{mL})\end{array}$ \\
\hline $430 \mathrm{PER}$ & 1.3 & $\mathrm{~N}$ & \\
\hline $8(\mathrm{C}) \mathrm{X}$ & $\mathrm{N}$ & 40 & \\
\hline 248 & $\mathrm{~N}$ & 755 & \\
\hline 237 & $\mathrm{~N}$ & 160 & \\
\hline $88 \mathrm{X}$ & $\mathrm{N}$ & 130 & \\
\hline $197 \mathrm{PER}$ & 2.1 & 100 & \\
\hline $252(\mathrm{~A})$ & 1.5 & 110 & \\
\hline 236 & 2.6 & & \\
\hline
\end{tabular}

* The indicated extremophiles were grown, the biomasses and broths separated and extracted as described in Materials and Methods. Each broth extract was tested for inhibition of $(1,3) \beta$-glucan synthase and ketol-isomerase activities as described. $\mathrm{N}=$ no effect. 
Fig. 2. Fractionation of Pseudomonas akbaalia extract.

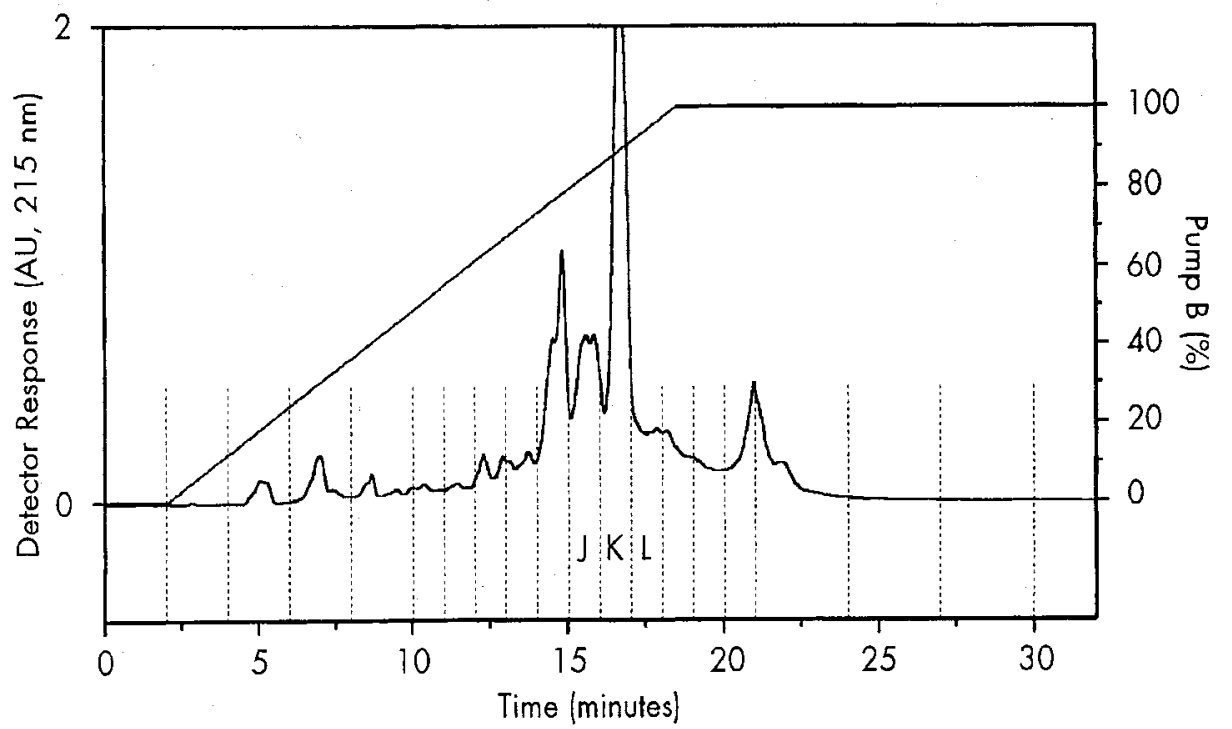

The fermentation broths of $80500-\mathrm{ml}$ cultures of $P$. akbaalia were grown, harvested and extracted with ethyl acetate as described in the Materials and Methods. The extract was separated by gradient elution (gradient shown in right-hand $\mathrm{Y}$-axis) and 18 fractions (each shown by dashed vertical lines) collected using the columns and conditions described in the Methods. The left-hand $Y$ axis is the absorbance at $215 \mathrm{~nm}$.

minifermentors, extracted the $\sim 40$ liters with ethyl acetate and separated the resulting ethyl acetate extract by HPLC as described in Materials and Methods. The elution results are shown in Figure 2. Each fraction of Figure 2 was assayed for antifungal activity using the $C$. albicans wholecell assay described in the Methods. Fractions $\mathrm{K}$ and L were the only fractions with antifungal activity (results not shown). Fractions $\mathrm{K}$ and $\mathrm{L}$ were further separated as described in the Methods and these results are shown in Figure $3 \mathrm{~A}$ for Fraction $\mathrm{K}$ and Figure $3 \mathrm{~B}$ for Fraction L. Each fraction was tested for antifungal activity using the $C$. albicans whole cell assay and fractions $\mathrm{K} 7, \mathrm{~K} 8$, and L7 were the only fractions with activity (not shown). Each of these fractions (i.e., $\mathrm{K} 7, \mathrm{~K} 8$ and L7) was subjected to MS and NMR analysis as described in the Methods in order to determine the structure of the active compound. In each case, the MS and NMR patterns were consistent to that of pyochelin and pyochelin derivatives (not shown). The structure of pyochelin is shown in Figure 4. To confirm that the antifungal activity was indeed due to pyochelin, we obtained bona fide pyochelin from Dr. C. Cox (University of Iowa) and determined that pyochelin had antifungal activity against $C$. albicans (SCHIMOLER, unpublished results).

\section{Discussion}

To our knowledge, we have discovered for the first time, antifungal activity from extracts of fermentation broths of extremophilic and thermophilic bacteria. From screening 217 organisms, we have identified 11 organisms that produced antifungal compounds. Of these, three organisms (430 PER, 197 PER and 8(C)X) were fungicidal against C. albicans, C. glabrata and A. fumigatus. None of the eleven organisms was active against chitin synthase activity, one organism (430 PER) extract inhibited $(1,3) \beta$-glucan synthase activity and four organism extracts inhibited ketolisomerase activity. The remaining 6 organism extracts inhibited either both $(1,3) \beta$-glucan synthase and ketolisomerase or neither enzyme-their mode(s) of action remain undetermined. The minimum inhibitory concentration values of 430 PER crude extracts against $C$. albicans and $A$. fumigatus $(<14 \mu \mathrm{g} / \mathrm{ml}$ and $31 \mu \mathrm{g} / \mathrm{ml}$, respectively [not shown]) clearly demonstrates the production of highly potent fungicidal compounds.

We chose to examine one organism in detail and determined that organism $8(\mathrm{C}) \mathrm{X}$ is a novel species of Pseudomonas (based on $16 \mathrm{~S}$ rDNA sequence comparisons). We have named this species Pseudomonas akbaalia. 
Fig. 3. Subfractionation of active fractions.
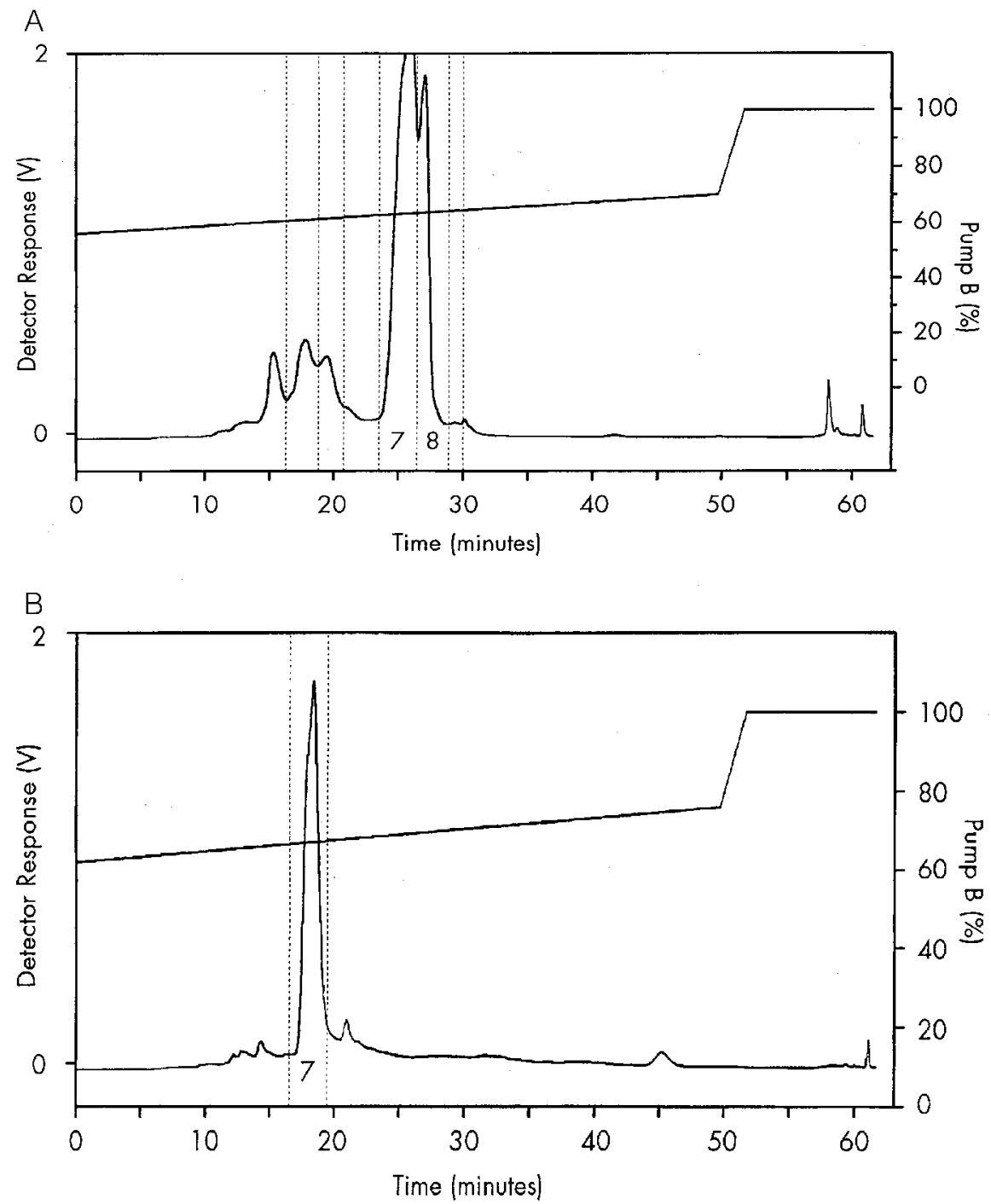

Fractions $\mathrm{K}$ and $\mathrm{L}$ of Figure 2 were subfractionated by HPLC as described in the Methods. A: Fraction K; B: Fraction L. Axes are as in Figure 2.

Fig. 4. Structure of pyochelin.<smiles>CN1C(C(=O)O)CSC1C1CSC(c2ccccc2O)=N1</smiles>

Importantly, we have identified an active component of the extract of the fermentation broth of Pseudomonas akbaalia as pyochelin, an iron-binding compound. Authentic pyochelin was also antifungal, confirming that pyochelin is in part responsible for the antifungal activity observed in the extract of the fermentation broth. Whether other active compounds are also present is not known at this time.

Taken together, our results indicate that at least 11 microorganisms warrant further investigation in order to identify the biologically active compounds present in the extracts. Importantly, the work presented in this manuscript points to extremophiles as an unexplored source of novel 
antifungal compounds. We are currently, under a Phase II SBIR project, screening an additional 400 organisms and preliminary results show that we have identified $\sim 36$ organisms with activity against $C$. albicans and $A$. fumigatus (WILSON et al., in preparation). These extracts are currently being fractionated to isolate and identify the active compound(s). These results will be the subject of future manuscripts elucidating the biological activities and structures of the active compounds.

\section{Acknowledgments}

This work was supported by a Phase I SBIR award to C. P. SelitrenNikoff of MycoLogics, Inc., (NIAID AI 40813). We would like to thank Ms. R. SCHIMOLER for performing the antifungal assays and to Dr. C. Cox (University of Iowa, Iowa City) for providing us with a sample of authentic pyochelin.

\section{References}

1) Herbrecht, R.: The changing epidemology of fungal infections: Are the lipid-based forms of amphotericin B an advance? European Journal of Haematology 56: $12 \sim 17,1996$

2) Cox, G. \& J. Perfect: Fungal infections. Current Opinion in Infectious Diseases 6: 422 426, 1993

3) FoX, J. L.: Fungal infection rates are increasing. ASM News 59: 515 518, 1993

4) Alexander, B. D. \& J. R. Perfect: Antifungal resistance trends towards the year 2000-Implications for therapy and new approaches. Drugs 54: 657 678, 1997

5) Bow, E. J.: Invasive fungal infections in patients receiving intensive cytotoxic therapy for cancer. British Journal of Haematology 101: 1 4, 1998

6) WARNOCK, D. W.: Fungal infections in neutropenia: current problems and chemotherapeutic control. Journal of Antimicrobial Chemotherapy 41: 95 105, 1998

7) Hood, S. \& D. W. Denning: Treatment of fungal infection in AIDS. Journal of Antimicrobial Chemotherapy 37: 71 85, 1996

8) Polis, M. A. \& J. A. Kovacs: Fungal infections in patients with the acquired immunodeficiency syndrome. In AIDS: Biology, Diagnosis, Treatment and Prevention, fourth edition. Eds., DEVITA, Jr., V. T., Hellman, S. and Rosenberg, S. A., pp. 231 244, Philadelphia: Lippincott-Raven, 1997

9) ClaRk, A. M.: The need for new antifungal drugs. In Approaches for Antifungal Drugs. Ed., FERnANDES, P. B. pp. 1 19, Boston, New Birkhauser, 1992

10) Stevens, D. A. \& K. Holmberg: Resistance to antifungal drugs: Current status and clinical implications. Curr. Opin. Anti-infective Invest. Drugs 1: 306 317, 1999

11) GraybiLl, J. R.: The future of antifungal therapy. Clinical Infectious Diseases 22 (Suppl. 2): S166 S178, 1996

12) Denning, D. W.: Echinocandins and Pneumocandins-a new antifungal class with a novel mode of action. J. Antimicrob. Chemother. 40: 611 614, 1997

13) ANON.: GM-237354. Drugs Future 22: 1221 1225, 1997

14) Gullo, V. P.: The discovery of natural products with therapeutic potential. Boston, Butterworth-Heinemann, 1994

15) SHu, Y.-Z.: Recent Natural Products Based Drug Development: A Pharmaceutical Industry Prospective. 61: 1053 1071, 1998

16) CragG, G. M.; D. J. Newman \& K. M. SNader: Natural products in drug discovery and development. J. Nat. Prod. 60: 52 60, 1997

17) Horikoshi, K. \& W. Grant: Superbugs p. 4, Japan Scientific Societies Press, Tokyo, 1991

18). StetTer, K: Hyperthermophiles: Isolation, Classification and Properties. Extremophiles: Microbiol Life in Extreme Environments. pp. 1 24, Wiley-Liss, Inc, 1998.

19) Brock, T. D.: Early Days in Yellowstone Microbiology. ASM News 64: 137 140, 1998

20) AdAmS, M. W. W. \& R. M. Kelly: Enzymes from microorganisms in extreme environments. Chem. Engineer. News 73: 32 42, 1995

21) Persidis, A: Extremophiles. Nature Biotechnol. 16: 593 594, 1998

22) Ankenbauer, R. G.; T. Toyokuni, A. Staley, K. RINEHART \& C. Cox: Synthesis and biological activity of pyochelin, a siderophore of Pseudomonas aeruginosa. J. Bacteriol. 170(11): 5344 5351, 1988

23) Combie, J.; K. RunNion \& M. Willlamson: Acquisition of heat stable enzymes from thermophilic microorganisms: peroxidases, ureases and glucose oxidase. CRDEC-CR-152, 1992

24) Runnion, K. \& J. Combie: Organic sulfur removal from coal by microorganisms from extreme environments. FEMS Microbial Review 11: 139 144, 1993

25) RunNion, K. \& J. CombiE: Microorganisms from extreme environments as source of thermally stable enzymes for removal of polyurethane aircraft coatings (Phase II), report prepared for Naval Surface Warfare Center, Silver Spring, MD, NSWCCD/TR-95/229, 1996

26) Combie, J. \& K. RunNion: Looking for diversity of Yellowstone extremophiles. J. Indust. Microbiol. 17: 214 218, 1996

27) Wood, R. L.; A. Wright, P. McCarthy, T. Miller, C. Taft, S. Pomponi \& C. P. Selitrennikoff: Characterization and optimization of in vitro assay conditions for $(1,3) \beta$-glucan synthase activity from Aspergillus fumigatus and Candida albicans for enzyme inhibition screening. J. Antibiotics 51: 665 675, 1998

28) Stackebrandt, E. \& B. Goebel: Taxonomic note: A place for DNA-DNA reassociation and $16 \mathrm{~S}$ rRNA sequence analysis in the present species definition in bacteriology. Int. J. Syst. Bacteriol. 44: 846 849, 1994

29) YARDEN, O. \& C. YANOFSKY: Chitin synthase I plays a major role in cell wall biogenesis in Neurospora crassa. Genes Development 5: 2420 2430, 1991

30) Seltrennikoff, C. P. \& G. OstrofF: Emerging therapeutic cell-wall targets in fungal infections. Emerging Therapeutic Targets 3: 53 72, 1999 